\title{
Effects of Light on Daytime Sleep in 12 Hours Night Shift Workers: A Field Study
}

\author{
Su Jung Choi ${ }^{1,2}$, Hea Ree Park ${ }^{3}$ Eun Yeon Joo ${ }^{4}$ \\ ${ }^{1}$ Department of Nursing, Samsung Medical Center, Seoul, \\ ${ }^{2}$ Department of Clinical Nursing Science, Graduate School of Clinical Nursing Science, Sungkyunkwan University, Seoul, \\ ${ }^{3}$ Department of Neurology, Inje University College of Medicine, Ilsan Paik Hospital, Goyang, \\ ${ }^{4}$ Department of Neurology, Samsung Medical Center, Sungkyunkwan University School of Medicine, Seoul, Korea
}

\author{
주간 수면 동안 빛 노출이 12 시간 교대근무자의 수면에 미치는 영향 \\ 최수정 ${ }^{1,2}$, 박혜리 ${ }^{3}$, 주은연 ${ }^{4}$ \\ 삼성서울병원 간호부, ${ }^{1}$ 성균관대학교 임상간호대학원, ${ }^{2}$ 인제대학교 의과대학 일산백병원 신경과, ${ }^{3}$ \\ 성균관대학교 의과대학 삼성서울병원 신경과 ${ }^{4}$
}

$\begin{array}{ll}\text { Received } & \text { April 24, 2019 } \\ \text { Revised } & \text { June 12, 2019 } \\ \text { Accepted } & \text { June 17, 2019 }\end{array}$

Address for correspondence

Eun Yeon Joo, MD, $\mathrm{PhD}$

Department of Neurology,

Samsung Medical Center,

Sungkyunkwan University

School of Medicine

81 Irwon-ro, Gangnam-gu,

Seoul 06351, Korea

Tel.: +82-2-3410-3599

Fax: +82-2-3410-0052

E-mail: ejoo@skku.edu
Objectives: Night shift workers suffer from sleep and daytime disturbances due to circadian misalignment. To investigate the role of environmental light in daytime sleep following $12 \mathrm{~h}$-night shift work. Methods: we enrolled $12 \mathrm{~h}$-shift female nurses working at one university-affiliated hospital $(\mathrm{n}=10$, mean age 26.6 years, shift work duration 3.8 years). This is a cross-over study to compare sleep between under light exposure (30 lux) and in the dark ( $<5$ lux) following $12 \mathrm{~h}$-night duty. Two sessions of experiments were underwent and the interval between sessions was about a month. Psychomotor vigilance test (PVT) had performed on awakening from sleep at each session and sleep-wake pattern had been monitored by actigraphy throughout the study period. Daytime sleep was also compared with night sleep of age-and gender matched daytime workers $(n=10)$. Results: Sleep parameters and PVT scores were not different between two light conditions. Activities during sleep seemed to be more abundant under 30 lux condition than in the dark, which was not significant. Compared to night sleep, daytime sleep of shift workers was different in terms of rapid eye movement (REM) sleep. Three shift workers showed sleep onset REM sleep and first REM sleep period was the longest during daytime sleep. Conclusions: Unexpectedly, daytime sleep of $12 \mathrm{~h}$ night shift workers was well-maintained regardless of light exposure. Early occurrence of REM sleep and shorter sleep latency during daytime sleep suggest that shift workers meet with misalignment of circadian rhythm as well as increased homeostatic sleep pressure drive.

J Sleep Med 2019;16(1):26-35

\section{서 론}

문명과 산업이 발달하면서 24시간 가동되는 직장이 많아 지고 교대근무자의 수도 증가하고 있다. 교대근무자는 내재 된 생체시계와 일치하지 않는 수면-각성으로 인해 수면장 애 및 건강 문제 외에도 업무 중 피로로 인한 사고 발생 위험 이 증가한다. 대표적인 교대근무자인 교대근무 간호사의 수 면장애 발생률은 주간 상근직 간호사에 비해 3배에 달하며, ${ }^{1}$ 간호사들은 불규칙한 교대근무로 인해 일주기리듬이 교란 되어 심한 피로와 더불어 수면부족과 교대근무 간 회복의
어려움을 경험한다. ${ }^{2}$

교대근무자는 근무조에 따라 수면시간을 포함한 수면 양 상에 차이를 보이는데, ${ }^{3,4}$ 특히 야간 근무 시 수면시간이 주 간 근무 시보다 적고, ${ }^{5}$ 근무 중 피로감이 더 심하다. ${ }^{6}$ 야간 근 무 시 피로와 졸음은 간호사들의 집중력을 떨어뜨려, ${ }^{7}$ 환자 관련 안전사고에도 영향을 미치는 것으로 보고되고 있다. ${ }^{8}$ 따라서 야간 근무 후 적절한 수면은 환자 안전관리에도 매 우 중요하다.

일반적으로 야간 근무 근로자는 주간 근무자에 비해 상대 적으로 긴 근무시간, 적은 신체활동, 주간 수면에 노출되는 
소음과 빛 등으로 인해 수면의 질이 낮은 것으로 알려져 있 다. ${ }^{9}$ 교대근무 간호사의 경우 근무조별 근무시간은 큰 차이 가 없고 업무 중 신체활동량도 차이가 없으나, 빛 노출량은 주간/오후 근무에 비해 야간 근무 시 취침 전과 주간 수면 중 에 유의하게 많은 것으로 나타났다. ${ }^{10}$ 건강한 정상인의 야간 수면 시에도 빛이 노출될 경우 암실 수면에 비해 얕은 수면 과 각성지수가 증가하고, 깊은 수면이 감소하였다. ${ }^{11}$ 따라서 야간 근무자의 주간 수면 시 빛 노출도 수면에 영향을 줄 것 으로 추정한다. 하지만 교대근무자의 주간 수면 시 빛 노출 을 조절하면서 수면의 질을 수면다원검사를 이용하여 객관 적으로 측정한 연구는 거의 없다.

이에 본 연구는 2 교대 근무 간호사를 대상으로 주간 수면 동안 노출되는 빛의 양에 따른 수면을 비교하고, 빛 노출 여 부와 집중력 및 야간 근무 동안의 피로도 간의 관련성을 파 악해보고자 한다. 또한 주간 상근직의 야간 수면과 비교하 여, 주간 수면과 야간 수면 간의 차이점을 분석하고자 한다. 이는 교대근무 간호사들의 수면 개선 중재를 위한 근거자료 로 활용될 것이다.

\section{방 법}

\section{대상자}

본 연구의 대상자는 서울 소재 1 개 상급종합병원에서 1 년 이상 야간 근무가 포함된 교대근무를 하고 있는 간호사 중, 연구 목적을 설명하고 연구에 참여할 것을 서면으로 동의한 여자 간호사를 대상으로 하였다. 남녀 간 수면 패턴의 차이 를 고려하여 남자 간호사는 제외하였다. ${ }^{12}$ 해당 병원은 8 시

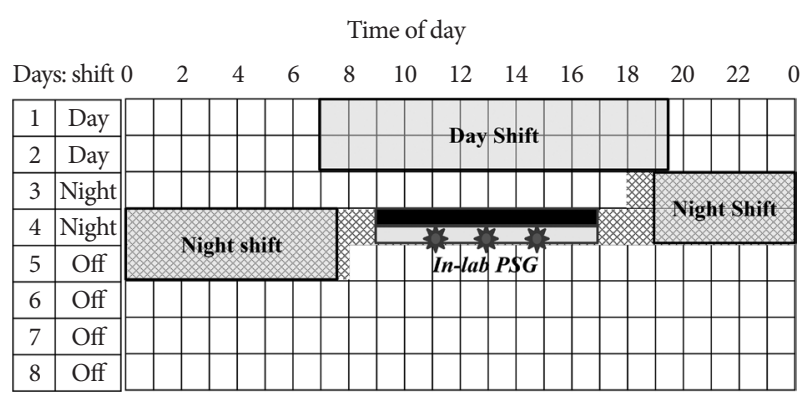

Period of wearing an Actiwatch

Period of in-lab PSG

Figure 1. Study framework and work schedules of $12 \mathrm{~h}$-shift nurses. The schedules of the participants (12 h-shift nurses) have the same schedule such as D12-D12-N12-N12 and then consecutive 4 off-days. Participants have worn the wrist Actiwatch Spectrum Pro $^{\circ}$ (Philips Resprionics) from one hour before 1st night shift work $(6 \mathrm{pm})$ to one hour after $2 \mathrm{nd}$ night shift work $(7 \mathrm{pm})$. Participants undergo in-lab PSG during daytime following 1st night shift. Two sessions of experiment are conducted and the interval is about 1 month. Condition-1 (30 lux) and condition-2 (<5 lux) are randomly assigned. PSG: polysomnography.
간 3교대 근무와 12 시간 2교대 순환근무가 함께 운영되고 있는데, 3교대의 경우는 근무 일정이 불규칙적이어서 야간 근무 전 근무 패턴이 서로 다를 수 있어 제외했다[주간 근무 (D12) 7:00 19:30, 야간 근무(N12) 19:00 7:30]. 2교대 근무 는 D12-D12-N12-N12-off(4 5일) 형태로 구성되어 있다 (Fig. 1). 단, 2교대 근무가 병동 근무 일정표 작성의 어려움 때문에 3교대와 완전하게 분리되어 있지 않아 2교대 근무 중에도 3 교대 근무가 일부 들어갈 수 있어서, 수면다원검사 시행 전 근무가 2교대로 진행된 경우에는 2교대로 간주하였 다. 본 연구는 예비연구로서, 수면장애를 갖고 있는 교대근 무자(불면증 심각도 지수 $\geq 15$ ) 10 명과 수면장애가 없는 상 근직 10 명을 모집하였다.

\section{연구 방법}

단일군 교차실험연구(cross-over design)이며, 수면다원 검사로 인한 첫날밤 효과(first night effects)를 최대한 배제 하고자 했다. 대상자 모집 및 자료 수집을 위해 연구 대상 병 원기관 윤리심의위원회(IRB)의 승인(승인번호 2018-05120)을 얻은 후 연구 목적을 설명하고 자발적 동의를 구한 후 시행하였다. 수면다원검사 동안의 조명 노출 순서 배정은 6 블록 무작위 배정(block randomization)에 의해 결정하였 고, 배정 순서는 R-program을 이용하여 생성된 난수표를 이용해 무작위로 배정하였다.

모든 대상자에게, 야간 근무가 연속 이틀 이상 있는 경우 의 첫 번째 근무에 들어가기 전 Actiwatch Spectrum Pro ${ }^{\circ}$ (Philips Resprionics, Murrysville, PA, USA)를 착용하게 했 다. 첫 번째 야간 근무 직후 간단하게 아침식사를 마친 후 수 면다원검사실에 내원해서 수면다원검사를 위한 준비를 시작 했다. 취침과 기상시간은 평소 야간 근무 후 취하는 수면시 간에 맞추었다. 17 시까지 깨지 못할 경우 다음 야간 근무 출 근을 위해서 17 시 30 분에 깨우고 검사를 종료하였다. 검사 직후 주관적 수면잠복기와 수면시간을 기술했으며, 수면 후 느끼는 피로감 정도를 평가했다(1점, 현재 매우 피곤하다 7 점, 현재 전혀 피곤하지 않다). 두 번째 야간 근무가 종료될 시점에 액티와치를 탈착 후 퇴근했다(Fig. 1). 첫 번째 검사 완료 후 한 달 이내 동일한 근무 형태가 되는 시점에서 같은 방식으로 액티와치 및 수면다원검사를 반복했다.

수면다원검사 동안의 조명 노출 조건은 다음과 같다.

- 조건 1(빛 노출): 선행연구에 근거해 교대근무 간호사 의 야간 근무 후 자택에서 수면을 취할 동안 노출되는 평균 조도(30 lux)로 유지 ${ }^{10}$

- 조건 2(빛 차단): 암실 상태(<5 lux)로 유지 조건의 순서는 무작위 배정에 의해 결정했다. 
자료 수집 기간은 2018년 8월부터 10월까지 시행되었고, 수집된 자료는 연구 대상자의 윤리적 측면을 고려하여 조사 내용과 결과는 모두 숫자로 처리하여 모든 자료가 비밀이 유지되도록 관리하였다.

대조군인 주간 상근직은 연구 시작 전 최소 7일 이상 액티 와치를 착용하여 일주기리듬 수면각성장애가 없음을 확인했 다. 야간 수면다원검사 동안 빛 차단(<5 lux)이 유지되었다.

\section{주간 수면다원검사}

수면다원검사는 Embla N7000(Embla, Reykjavik, Iceland)을 이용하였다. 기본 검사 항목으로 6채널의 뇌파(C3$\mathrm{A} 2, \mathrm{C} 4-\mathrm{A} 1, \mathrm{~F} 3-\mathrm{A} 2, \mathrm{~F} 4-\mathrm{A} 1, \mathrm{O} 1-\mathrm{A} 2, \mathrm{O} 2-\mathrm{A} 1)$ 와 4채널의 안 전위도(electro-oculogram), 1채널의 턱근전도(chin electro-myogram)를 기록하여 수면의 단계와 각성 빈도를 측정 하였다. 호흡 관련 측정을 위해서 압력센서를 이용하여 비강 공기압을 측정하였다. 호흡 노력을 보기 위해 흥곽과 복부벨 트를 이용하여 호흡 움직임을 측정하였다. Oximetry를 이용 하여 검지손가락에서 산소포화도를 측정하였고, 소리 센서 로 코골이 강도를 측정하였다. 다리 움직임을 보기 위해 2채 널의 양측 전경골근(anterior tibialis)의 근전도를 측정하였 다. 수면 자세를 확인하는 체위 센서와 심전도를 함께 측정 하며 동시에 비디오를 기록하여 수면 중 행동장애나 자세를 기록하였다.

수면 단계와 호흡지수 등 수면다원검사 평가는 American Academy of Sleep Medicine Manual에 따라 판독되었다. ${ }^{13}$ 수면 구조는 뇌파, 근전도, 안구 움직임 등을 통해 수면 단계 를 분석한 것으로, N1, N2, N3, rapid eye movement(REM) 수면의 비율로 조사하였다. 수면 양상은 수면잠복기(sleep latency), 입면 후 각성시간(wakefulness after sleep onset), 총 수면시간(total sleep time), 수면 효율(sleep efficiency)로 측정하였고, 각성지수(arousal index) 등을 평가하였다.

\section{액티와치(Actigraphy)}

액티와치는 움직임에 기반하여 수면-각성을 측정할 수 있는 Actiwatch Spectrum Pro ${ }^{\circledR}$ 를 이용하였다. 비우세 손목 에 착용하고 손목에서 측정된 활동량과 조도는 Actiware version 5.70 sleep software(Philips Resprionics)를 이용해 서 분석하였다. 손목 움직임의 강도와 빈도는 초당 $32 \mathrm{cycle}$ 빈도로 지속적으로 측정되며, 측정된 움직임 강도는 2 분 에 폭(epoch)의 평균값으로 기록하였다. 모든 에폭의 움직임 수치들은 프로그램 알고리즘의 역치 계산에 의해 각성 (wake) 또는 수면(sleep)이라는 이진수로 변환될 수 있다. ${ }^{14}$ 그러나 액티와치 기록이 실제 잔 것인지는 정확히 알 수 없
으므로 active와 rest로 기술하였고, 이 방법을 이용해서 근 무시간대(19시부터 07시)와 근무 후 시간대(07시부터 19시) 의 activity의 정도를 매 시간별 평균값으로 정량적으로 분석 하였다. 07시부터 07시 30분까지는 인수인계 시간이나 병동 에 따라서는 일찍 마치는 경우도 있어 07시부터 근무 후 시 간으로 간주하였다. Actigraphy에서 각각 rest 및 active로 평 가된 에폭 수에 2 를 곱하여 근무 및 수면시간 동안 매 시간 별 rest와 active period의 duration을 측정하였다. 조도량도 활동량과 마찬가지로 2 분 간격으로 측정되었으며, 활동량과 같은 방법으로 근무 시간대와 근무 후 시간대를 측정하였고, 추가로 수면검사 시작 전 5 시간 동안의 평균 빛 노출량도 분 석하였다.

\section{Psychomotor vigilance test}

지속적 집중력과 각성도를 평가하는 검사로 수면다원검사 실에서의 주간 수면 직후 5 분 이내에 수면다원검사 당시와 동일한 조명하에서 시행하였다. iPadMini(Foxconn, Taipei, Taiwan)를 이용하여 모니터에 무작위로 수 초 간격으로 제 시되는 시각적 자극을 보는 즉시 버튼을 누르게 하였다. 검 사 소요시간은 약 3 분 정도이며, 눈의 자극을 최소화하기 위 해 tablet display 밝기는 최대치에서 70\% 정도로 맞추었다. 사용한 프로그램은 3-min psychomotor vigilance test(PVT) 로 Joggle Research software, version 2.4(Joggle Research, Inc., Seattle, WA, USA)를 사용하였으며, PVT 검사를 통해 반응 속도, 누락 오류 수, 커미션 오류 수 등을 확인하였다.

\section{설문지}

대상자는 한글판 불면증 심각도지수(Insomnia Severity Index, ISI), ${ }^{15}$ 엡워스 주간졸림증 척도(Epworth Sleepiness Scale, ESS), ${ }^{16}$ 일주기 척도(Morningness-Eveningness Questionnaire $)^{17}$ 를 연구 등록 시점에서 작성했다. 그 외 일반적 특성으로 결혼 상태, 학력, 근무 경력, 체질량, 생활 습관(흡 연, 음주), 동반 건강 문제, 평소 야간 근무와 야간 근무 사이 수면 습관, 실험 세팅의 주간 수면 전날 즉, 첫 번째 야간 근 무 전날의 주관적으로 인지한 수면시간 등을 조사하였다.

\section{자료분석 방법}

수집된 자료는 유의수준 0.05 로 하여 SPSS WIN version 18.0(SPSS Inc., Chicago, IL, USA)을 이용하여 다음과 같이 분석한다. 대상자의 일반적 특성과 수면다원검사 결과, 액티 와치로 측정한 활동량 및 설문 자료는 빈도와 백분율, 평균 과 표준편차를 이용하였다. 빛 노출 유무에 따른 결과의 차 이는 Wilcoxon signed rank test를 시행하여 분석하였다. 


\section{결 과}

\section{일반적 특성}

평균 연령은 26.70 3.89 세(24 37세)였고, 기혼자는 2명 (20\%)이었다. 동반 건강 문제로 만성피로가 $80 \%$ 로 가장 많 았고, 속쓰림을 호소하는 경우가 70\%였다. 평균 체질량지수 는 $19.87 \pm 2.64 \mathrm{~kg} / \mathrm{m}^{2}$ 였으며, 카페인 섭취는 평균 하루 1.7 잔이었다. 일주기 유형은 저녁형이 6명으로 가장 많았다. 엡 워스 주간졸림증 척도 평균은 8.0점이었고, 과도한 주간졸음 을 호소하는 경우 $(\mathrm{ESS} \geq 10)$ 가 3 명이었다. 야간 근무 후 주 간 수면습관을 살펴보면, 자가 보고한 수면시간은 평균 4.85 \pm 1.36 시간, 낮잠을 포함한 총 수면시간은 $5.05 \pm 1.14$ 시간 이었다(Table 1).

\section{빛 노출에 따른 수면 관련 지표 간의 비교(조건 1 대 조건 2 )}

\section{수면다원검사}

조건 1(빛 노출 $30 \mathrm{lux}$ )과 조건 2(빛 제한 <5 lux) 실험에 들어가기 전의 수면시간 간에 유의한 차이가 없었다. 조건 1 과 조건 2 실험의 수면다원검사 지표 간에도 차이를 보이지 않았다. 주간 수면임에도 불구하고, 수면지표는 모두 정상 범주였으며, 무호흡-저호흡지수(apnea-hypopnea index)도

Table 1. Demographic and clinical characteristics of the participants $(n=10)$

\begin{tabular}{|c|c|c|c|}
\hline Variables & $\mathrm{n}(\%)$ & Mean \pm SD & Range \\
\hline Age, years & & $26.70 \pm 3.89$ & $24-37$ \\
\hline Marital status: single & $8(80.0)$ & & \\
\hline Education: bachelor & $10(100)$ & & \\
\hline Work experience, years & & $3.99 \pm 3.88$ & $1.2-14.3$ \\
\hline $\mathrm{BMI}, \mathrm{kg} / \mathrm{m}^{2}$ & & $19.87 \pm 2.64$ & $15.2-24.1$ \\
\hline Habitual caffeine, cups/day & & $1.65 \pm 1.03$ & $0.5-3.0$ \\
\hline Non-drinker & $3(30.0)$ & & \\
\hline Habitual drinking, glasses/week & & $2.00 \pm 2.53$ & $0-8$ \\
\hline \multicolumn{4}{|l|}{ Comorbid health problem } \\
\hline Chronic fatigue & $8(80.0)$ & & \\
\hline Heartburn & $7(70.0)$ & & \\
\hline Constipation & $4(40.0)$ & & \\
\hline Diarrhea & $2(20.0)$ & & \\
\hline Depressive mood & $2(20.0)$ & & \\
\hline Anxiety & $1(10.0)$ & & \\
\hline Irregular menstruation & $4(40.0)$ & & \\
\hline MEQ & & $44.90 \pm 11.46$ & $30-72$ \\
\hline Morning type & $1(10.0)$ & & \\
\hline Intermediated type & $3(30.0)$ & & \\
\hline Evening type & $6(60.0)$ & & \\
\hline Insomnia Severity Index & & $18.80 \pm 3.01$ & $15-24$ \\
\hline ESS & & $8.00 \pm 2.75$ & $4-13$ \\
\hline Excessive daytime sleepiness (ESS $\geq 10$ ) & $3(30.0)$ & & \\
\hline \multicolumn{4}{|l|}{ Habitual sleep after 1st night shift } \\
\hline Time to bed, clock h & & $9.70 \pm 0.60$ & $9.0-10.5$ \\
\hline Time out of bed, clock h & & $14.90 \pm 1.43$ & $12.0-17.5$ \\
\hline Time in bed, $\mathrm{h}$ & & $5.20 \pm 1.51$ & $3.0-7.5$ \\
\hline Sleep duration, $\mathrm{h}$ & & $4.85 \pm 1.36$ & $3.0-7.0$ \\
\hline Nap, h & & $0.20 \pm 0.42$ & $0-1.0$ \\
\hline $24 \mathrm{~h}$ total sleep time, $\mathrm{h}$ & & $5.05 \pm 1.14$ & $3.0-7.0$ \\
\hline
\end{tabular}

SD: standard deviation, BMI: body mass index, MEQ: Morningness-Eveningness Questionnaire, ESS: Epworth Sleepiness Scale 
Table 2. Polysomnography-based daytime sleep parameters according to environmental light $(n=10)$

\begin{tabular}{|c|c|c|c|c|}
\hline Variables & Condition 1 (30 lux) & Condition $2(<5$ lux $)$ & $\mathrm{z}$ & $p$ \\
\hline \multicolumn{5}{|c|}{ Subjectively reported sleep schedule before 1st night shift } \\
\hline Time to bed, clock h & $0.10 \pm 2.84$ & $0.25 \pm 1.62$ & -0.51 & 0.959 \\
\hline Time out of bed, clock h & $10.45 \pm 2.48$ & $9.75 \pm 2.87$ & -1.02 & 0.309 \\
\hline Time in bed, $\mathrm{h}$ & $10.35 \pm 3.15$ & $9.50 \pm 2.38$ & -0.83 & 0.405 \\
\hline Seep duration, $\mathrm{h}$ & $9.60 \pm 2.38$ & $9.20 \pm 2.63$ & -0.68 & 0.496 \\
\hline Sleep efficiency, \% & $94.26 \pm 8.54$ & $96.67 \pm 10.54$ & -0.67 & 0.500 \\
\hline Nap, h & $0.70 \pm 0.98$ & $1.35 \pm 1.42$ & -0.99 & 0.324 \\
\hline $24 \mathrm{~h}$ sleep, $\mathrm{h}$ & $10.25 \pm 2.46$ & $10.55 \pm 2.88$ & 0.31 & 0.758 \\
\hline \multicolumn{5}{|l|}{ Polysomnography data } \\
\hline Time in bed, $\mathrm{h}$ & $5.54 \pm 1.23$ & $5.61 \pm 1.61$ & -0.10 & 0.919 \\
\hline Total sleep time, $\mathrm{h}$ & $4.99 \pm 1.28$ & $5.01 \pm 1.63$ & -0.26 & 0.799 \\
\hline Sleep latency, $\min$ & $2.15 \pm 1.81$ & $3.35 \pm 5.43$ & -0.62 & 0.537 \\
\hline REM latency, min & $52.55 \pm 34.39$ & $63.30 \pm 32.81$ & -0.76 & 0.445 \\
\hline WASO, $\%$ & $10.30 \pm 7.52$ & $10.49 \pm 7.09$ & -0.05 & 0.959 \\
\hline Sleep efficiency, \% & $89.17 \pm 7.46$ & $88.68 \pm 6.88$ & -0.36 & 0.721 \\
\hline N1 sleep, \% & $12.89 \pm 7.80$ & $10.59 \pm 7.09$ & -1.79 & 0.074 \\
\hline N2 sleep, \% & $42.22 \pm 9.26$ & $37.31 \pm 9.67$ & -0.97 & 0.333 \\
\hline N3 sleep, \% & $20.64 \pm 10.86$ & $28.38 \pm 14.86$ & -1.99 & 0.047 \\
\hline REM sleep, \% & $24.28 \pm 3.57$ & $23.72 \pm 6.24$ & -0.56 & 0.575 \\
\hline Total arousal index, /h & $12.44 \pm 4.65$ & $12.82 \pm 6.77$ & -0.06 & 0.953 \\
\hline Spont. arousal index, /h & $10.50 \pm 3.74$ & $11.31 \pm 7.25$ & -0.05 & 0.959 \\
\hline Movement arousal index, /h & $0.23 \pm 0.34$ & $0.08 \pm 0.19$ & -1.89 & 0.059 \\
\hline REM arousal index, /h & $8.57 \pm 4.11$ & $11.57 \pm 4.28$ & -1.68 & 0.092 \\
\hline AHI, /h & $0.99 \pm 1.40$ & $1.25 \pm 2.65$ & -0.36 & 0.722 \\
\hline Estimated total sleep time, $\mathrm{h}$ & $5.20 \pm 0.89$ & $5.15 \pm 1.56$ & 0.00 & $>0.999$ \\
\hline Estimated sleep latency, min & $11.70 \pm 9.76$ & $11.00 \pm 9.94$ & -0.52 & 0.602 \\
\hline Perceived fatigue after sleep & $3.60 \pm 1.36$ & $4.60 \pm 0.92$ & -1.62 & 0.125 \\
\hline
\end{tabular}

REM: rapid eye movement, WASO: wakefulness after sleep onset, Spont.: spontaneous, AHI: apnea-hypopnea index

Table 3. Intensity of activities and light, and rest/active period by actigraphy

\begin{tabular}{|c|c|c|c|c|c|c|}
\hline Period & Variables & $\begin{array}{l}\text { Condition } 1 \\
(30 \operatorname{lux})\end{array}$ & $\begin{array}{c}\text { Within } \\
p^{*}\end{array}$ & $\begin{array}{l}\text { Condition } 2 \\
(<5 \operatorname{lux})\end{array}$ & $\begin{array}{l}\text { Within } \\
p^{* *}\end{array}$ & $\begin{array}{c}\text { Between } \\
p^{* * *}\end{array}$ \\
\hline \multirow{6}{*}{$\begin{array}{l}\text { Night-work } \\
\text { period } \\
(19: 00-07: 00)\end{array}$} & 1st NS activities & $456.01 \pm 161.05$ & 0.445 & $336.82 \pm 228.68$ & 0.878 & 0.508 \\
\hline & 2nd NS activities & $464.77 \pm 168.54$ & & $346.72 \pm 264.00$ & & 0.445 \\
\hline & 1st NS rest period, min & $22.80 \pm 15.61$ & 0.539 & $20.50 \pm 18.72$ & 0.683 & 0.444 \\
\hline & 2nd NS rest period, min & $27.50 \pm 18.35$ & & $26.40 \pm 23.74$ & & 0.539 \\
\hline & 1st NS light, lux & $806.05 \pm 541.82$ & 0.285 & $779.11 \pm 523.77$ & 0.646 & 0.799 \\
\hline & 2nd NS light, lux & $678.58 \pm 345.10$ & & $703.82 \pm 444.30$ & & 0.878 \\
\hline $\begin{array}{l}5 \mathrm{~h} \text { light before } \\
\text { starting PSG, lux }\end{array}$ & & $559.50 \pm 393.10$ & & $366.35 \pm 165.24$ & & 0.103 \\
\hline \multirow{3}{*}{$\begin{array}{l}\text { Non-working } \\
\text { period } \\
(07: 00-19: 00)\end{array}$} & Activities & $245.36 \pm 117.06$ & & $147.03 \pm 91.66$ & & 0.074 \\
\hline & Active period, min & $185.20 \pm 30.68$ & & $175.50 \pm 34.34$ & & 0.066 \\
\hline & Light, lux & $151.26 \pm 104.02$ & & $123.58 \pm 52.85$ & & 0.575 \\
\hline
\end{tabular}

*comparison of 1st NS and 2nd NS in condition 1 (30 lux), ${ }^{* *}$ comparison of 1st NS and 2 nd NS in condition $2(<5$ lux $),{ }^{* * *}$ comparison of condition 1 (30 lux) and condition $2(<5$ lux $)$. NS: night shift, PSG: polysomnography 
정상이었다. 수면잠복기는 조건 1과 조건 2 실험 모두에서 3 분 내외로 매우 짧아져 있어서, 야간 근무 후 수면 욕구가 증 가되었음을 추정할 수 있다. 수면다원검사 직후 작성한 주관 적 잠복기는 실제보다 길게 평가하였으나, 주관적 수면시간 은 실제 수면시간과 유사하게 추정했으며, 두 조건 간 차이 는 없었다(Table 2).

\section{액티와치}

조건 1(30 lux) 실험의 수면검사 동안 활동량(즉, 뒤척임)이 조건 2(<5 lux)의 수면 동안보다 더 많았고, 15 시 이후에는 active로 기록된 시간이 더 길었으나 시간대별 통계적인 차이 는 없었다(Table 3). 야간 근무 중 02 03시에 rest로 기록된 시간은 조건 1 과 조건 2 실험 모두에서 다 길었지만, 두 군 간 에 유의한 차이는 없었다(Fig. 2). 첫 번째 야간 근무 시작 전 부터 두 번째 야간 근무를 마칠 때까지 측정된 rest-active 주 기와 전체 활동량은 조건 1 과 2 실험 간에 차이가 없었다.

조도량을 비교한 결과도 조건 1 과 조건 2 간 근무 중과 근

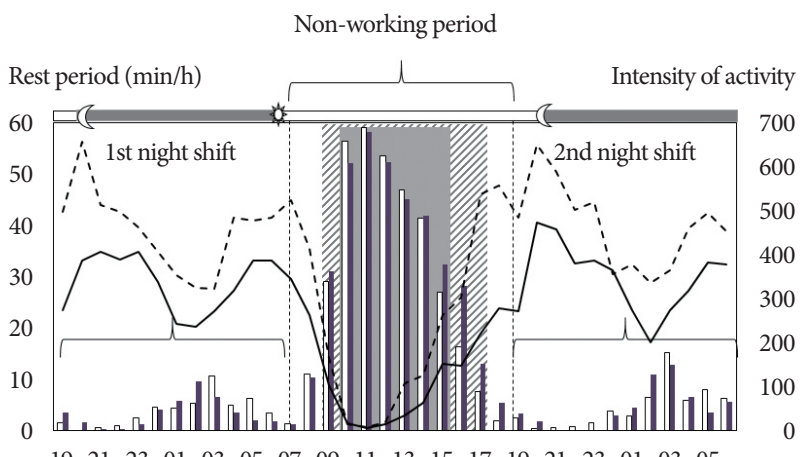

$\begin{array}{llllllllllllllllll}19 & 21 & 23 & 01 & 03 & 05 & 07 & 09 & 11 & 13 & 15 & 17 & 19 & 21 & 23 & 01 & 03 & 05\end{array}$

Clock hour

\begin{tabular}{|c|c|c|}
\hline$\square$ & Rest period (30 lux) & Rest period ( $<5$ lux $)$ \\
\hline$-\cdots$ & Activity (30 lux) & Activity $(<5 \operatorname{lux})$ \\
\hline
\end{tabular}

Figure 2. Distributions of rest period and activities during 1st and 2nd night shifts and intervening sleep period; actigraphy data. Rest period is presented during night shifts working time. Compared to 1st night shift, rest period in 2-5 am seems to be higher in both conditions ( 1 and 2 ) of 2 nd night shift, but not statistically significant. Hourly rest period (time) in each clock hour. Condition 1 (30 lux): white bars and dotted lines, condition 2 ( $<5$ lux): black bars and solid lines.

Table 4. Psychomotor vigilance test after daytime sleep according to environmental light $(n=10)$

\begin{tabular}{lcccc}
\hline \multicolumn{1}{c}{ Variables } & Condition 1 (30 lux) & Condition 2 $(<5$ lux $)$ & z & $p$ \\
\hline Mean RT, msec & $292.05 \pm 44.21$ & $266.64 \pm 31.07$ & -1.78 & 0.074 \\
Mean 1/RT & $3.79 \pm 0.43$ & $4.03 \pm 0.43$ & -1.48 & 0.139 \\
Slowest 10\% 1/RT & $2.24 \pm 0.64$ & $2.46 \pm 0.51$ & -1.58 & 0.114 \\
Number of lapse & $6.20 \pm 6.01$ & $4.10 \pm 2.77$ & -1.14 & 0.256 \\
Lapse probability, \% & $14.27 \pm 13.79$ & $9.37 \pm 6.17$ & -1.17 & 0.241 \\
Number of false start & $0.90 \pm 1.85$ & $1.60 \pm 1.51$ & -1.19 & 0.235 \\
\hline
\end{tabular}

RT: reaction time

Table 5. Comparison of daytime sleep in shift-workers and night time sleep in day-workers

\begin{tabular}{|c|c|c|c|c|c|}
\hline \multirow[b]{2}{*}{ Variables } & \multicolumn{3}{|c|}{ Daytime sleep } & \multirow{2}{*}{$\begin{array}{c}\text { Night sleep } \\
\text { healthy control } \\
(\mathrm{n}=10)\end{array}$} & \multirow[b]{2}{*}{$p$} \\
\hline & $\begin{array}{c}\text { Condition } 1 \\
(30 \operatorname{lux})\end{array}$ & $\begin{array}{c}\text { Condition } 2 \\
(<5 \operatorname{lux})\end{array}$ & $\begin{array}{c}\text { Total } \\
(\mathrm{n}=20)\end{array}$ & & \\
\hline \multicolumn{6}{|l|}{ Sleep parameters } \\
\hline N1 sleep/TST, \% & $12.86 \pm 7.80$ & $10.59 \pm 7.09$ & $11.73 \pm 6.90$ & $10.64 \pm 5.81$ & 0.812 \\
\hline N2 sleep/TST, \% & $42.22 \pm 9.26$ & $37.31 \pm 9.67$ & $39.77 \pm 9.55$ & $50.32 \pm 6.09$ & 0.005 \\
\hline N3 sleep/TST, \% & $20.64 \pm 10.86$ & $28.38 \pm 14.86$ & $24.51 \pm 13.27$ & $16.52 \pm 6.15$ & 0.091 \\
\hline REM sleep/TST, \% & $24.28 \pm 3.57$ & $23.72 \pm 6.24$ & $24.00 \pm 4.96$ & $22.50 \pm 5.20$ & 0.350 \\
\hline Total sleep time, $\mathrm{h}$ & $4.99 \pm 1.28$ & $5.01 \pm 1.63$ & $5.00 \pm 1.43$ & $5.41 \pm 0.29$ & 0.812 \\
\hline Sleep efficiency, \% & $89.17 \pm 10.95$ & $88.68 \pm 6.88$ & $88.93 \pm 6.99$ & $91.95 \pm 3.61$ & 0.328 \\
\hline \multicolumn{6}{|l|}{ REM sleep distribution } \\
\hline REM latency, min & $63.10 \pm 31.80$ & $63.30 \pm 32.81$ & $63.10 \pm 31.44$ & $84.10 \pm 40.34$ & 0.422 \\
\hline 1st REM/1-3 REM, \% & $43.77 \pm 27.21$ & $42.26 \pm 25.70$ & $43.02 \pm 25.77$ & $24.35 \pm 12.54$ & 0.043 \\
\hline 2nd REM/1-3 REM, \% & $30.34 \pm 16.80$ & $38.00 \pm 21.94$ & $34.17 \pm 19.42$ & $36.89 \pm 12.56$ & 0.253 \\
\hline 3rd REM/1-3 REM, \% & $25.90 \pm 22.72$ & $19.74 \pm 17.84$ & $22.82 \pm 20.13$ & $38.77 \pm 8.02$ & 0.033 \\
\hline
\end{tabular}

Statistical analysis was done by independent samples Mann-Whitney U test between daytime sleep ( $\mathrm{n}=20)$ and night sleep ( $\mathrm{n}=10)$. TST: total sleep time, REM: rapid eye movement 


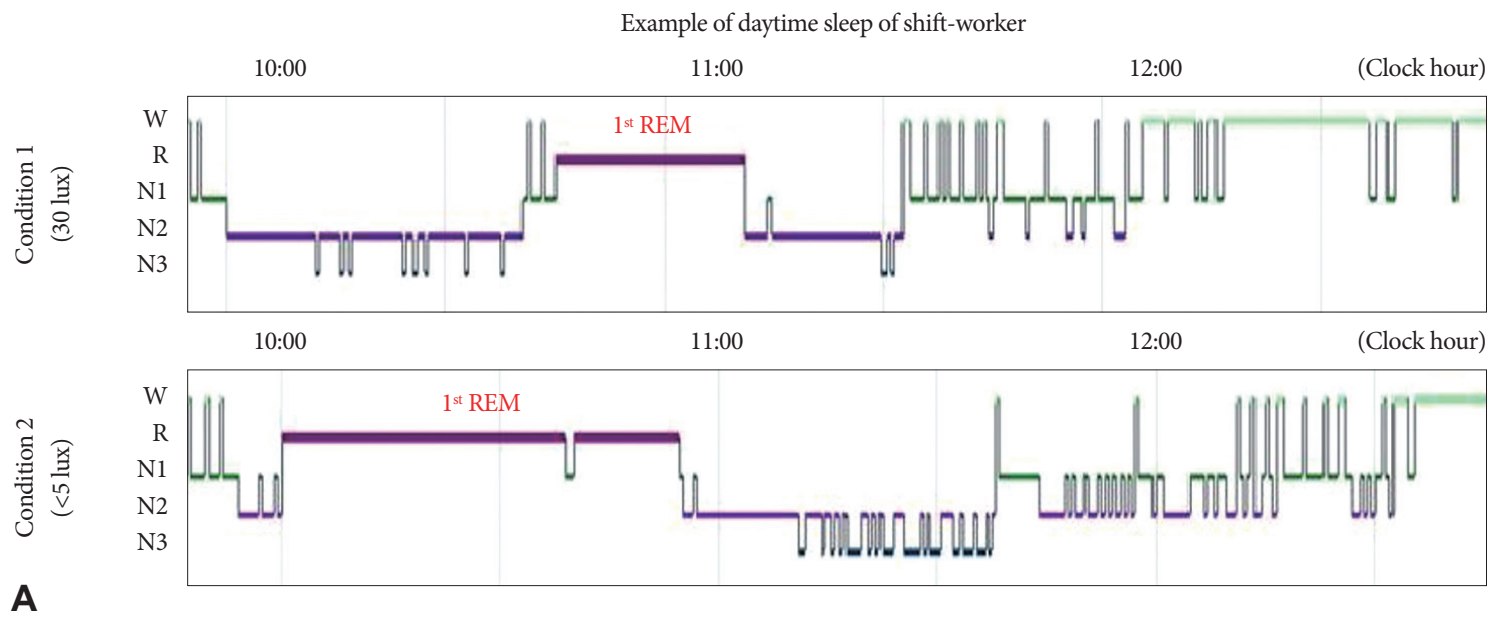

A

Example of nocturnal sleep of healthy day-worker

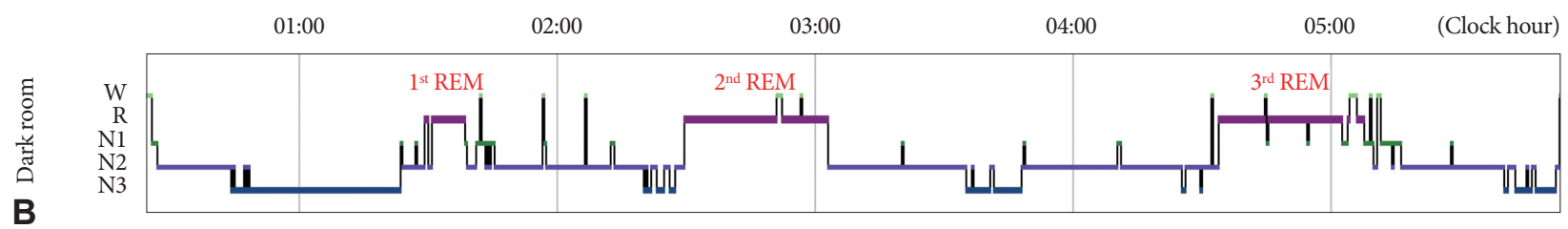

Figure 3. Comparison of hypnogram between daytime sleep and night sleep of daytime workers in polysomnography. (A) An example of daytime sleep of a shift-worker (subject 4, 25 years old). The top image is daytime sleep in condition 1 (30 lux), and the lower image is daytime sleep in condition 2 ( $<5$ lux). (B) An example of night sleep of a healthy day-worker. Compared to night sleep, the number of REM sleep is decreased and the occurrence of REM sleep is earlier during daytime sleep. W: waking, R: REM sleep (\%), N1: N1 sleep (\%), N2: N2 sleep (\%), N3: N3 sleep (\%), REM: rapid eye movement.

무 후의 빛 노출량에 차이를 보이지 않았으며, 시간대별 분 석결과도 통계적 유의한 차이는 보이지 않았다. 주간 수면을 취하기 전(수면다원검사를 시작하기 전) 5 시간 동안 빛 노출 정도를 분석한 결과도 유의한 차이는 없었다 $(p=0.103)$.

\section{PVT}

조건 1(30 lux)과 조건 2(<5 lux) 실험의 수면검사 직후 측 정한 집중력과 각성도 간의 유의한 차이는 없었다(Table 4).

\section{2교대 근무자와 주간 상근자의 수면 비교}

교대근무자의 주간 수면(조건 110 건, 조건 210 건, 20건의 통합)과 주간 상근자의 야간 수면 10건을 비교한 결과, 주간 수면의 N2 sleep \%가 39.8\%로 야간 수면에 비해 유의하게 낮은 것으로 나타났으며 $(\mathrm{z}=-2.71, p=0.005)$, 이는 주간 수면 에서 N3 sleep \%가 24.5\%로 증가하면서 N2 sleep \%가 감소 한 것으로 보인다(Table 5). 그 외 다른 지표는 차이를 보이 지 않았다.

주간 수면 동안의 REM 수면 분포는 야간 수면과 다른 양 상을 보였다. 교대근무자의 주간 수면과 상근자의 야간 수면 의 수면도(hypnogram)의 렘수면 분포에서 차이를 보였다 (Fig. 3, 4). 교대근무자의 주간 수면에서, 첫 번째 렘수면이 다른 주기보다 더 길게 지속되는 양상을 보였다. 이를 정량
적으로 분석하기 위하여 첫 번째 렘수면이 전체 렘수면 시 간에서 차지하는 비율을 구했다.

교대근무자의 주간 수면의 첫 렘수면은 전체 렘수면의 $43.02 \pm 25.77 \%$ 를 차지하며, 상근자의 야간 수면의 첫 렘수 면은 $24.35 \pm 12.54 \%$ 여서, 두 군 간의 유의한 차이를 보였다 ( $\mathrm{z}=-2.02, p=0.043)$. 두 번째 렘수면 지속시간은 두 군 간 차 이를 보이지 않았고, 세 번째 렘수면은 상근자의 야간 수면 에서 더 길게 지속되었다 $38.77 \pm 8.02 \%$ vs. $22.82 \pm 20.13 \%$, $\mathrm{z}=-2.71, p=0.033)$.

세 번째 이후의 렘수면은 주간 수면 20건 중 11건에서, 야 간 수면 10 건 중 6 건에서 나타나지 않아 분석하지 않았다.

\section{고 찰}

본 연구는 야간 근무 후 주간 수면 동안 노출되는 빛에 따 른 수면의 질 및 다음 날 집중력과 연속되는 야간 근무 동안 의 졸음 정도를 파악하고자, 12 시간 2 교대 근무를 하는 간호 사 10 명을 대상으로 수행했다.

교대근무자의 주간 수면 동안에는 환경적 빛에 노출이 될 가능성이 높기 때문에, 수면의 질이 떨어지고 기상 후 집중 도도 아울러 감소하여 다음 날 야간 근무에 방해가 될 것으 로 예상했다. 본 연구가 10 명을 대상으로 한 예비조사이긴 


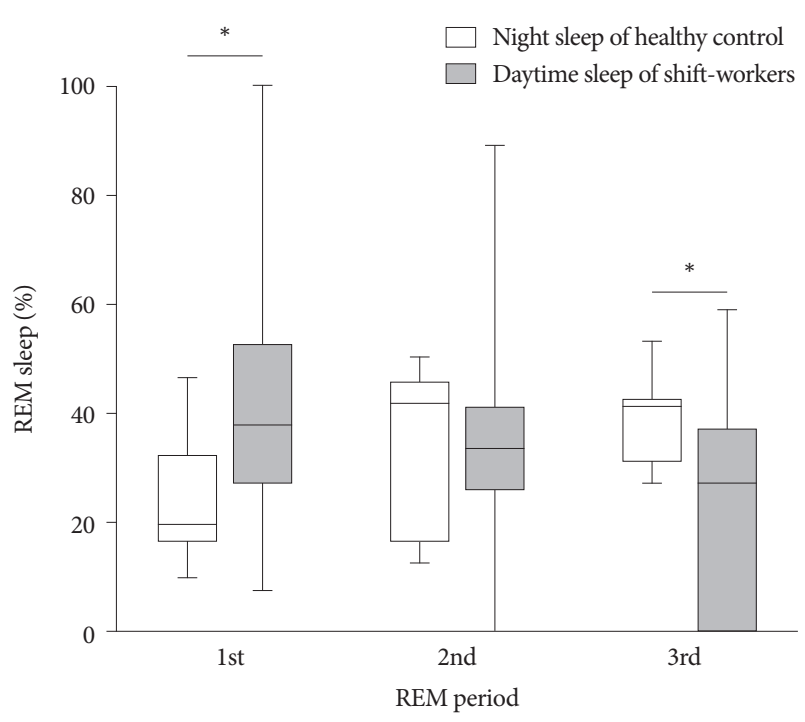

Figure 4. Comparison of REM sleep distribution of the first three REM sleep between night and daytime sleep. Box plot represents median, interquartile range, minimum, and maximum of each REM sleep distribution of the first three REM sleep. REM distribution is expressed a percentage of each REM sleep duration of each sleep cycle divided by the first three REM sleep duration. ${ }^{*} p<0.05$ independent samples Mann-Whitney $U$ test. White box is the night sleep of healthy day-workers $(n=10)$, and gray box is the daytime sleep of shift-workers $(n=20)$, respectively. REM: rapid eye movement.

하나, 가설과 다른 결과가 도출되었다. 본 연구에 참여한 교 대근무 간호사들은 사전 인터뷰와 설문조사에서 모두 주간 수면 동안의 심각한 수면장애(잠들기 어려움, 수면시간 지 속이 어려움 등)를 호소한 바 있다(ISI>15). 하지만 $30 \mathrm{lux}$ 의 빛 노출을 시킨 결과, 암실 상황과 유사하게 수면지표와 기 상 후 집중도 평가가 모두 정상 수준으로 나타났으며, 이는 상근자의 야간 수면 결과와 비교하여도 임상적으로 유의한 차이가 없었다. 피험자의 조건이 다르긴 하나, 빛 노출이 수 면에 미치는 영향만 고려한다면 본 연구진의 이전 연구 결 과와도 일치하지 않는다: 상근자의 야간 수면 동안 $40 \mathrm{lux}$ 빛에 노출했을 때, 암실 조건보다 N1 수면 \%와 각성지수가 증가하고, $\mathrm{N} 3$ 수면 \%는 감소함을 보인 선행연구 결과와의 차이점을 다음의 몇 가지 추정으로 설명해보고자 한다. ${ }^{11}$

첫째, 피험자들은 집에 퇴근하지 않고 병원에서 근무를 끝 내자마자 실험실에서 검사를 시행하였기 때문에 밝은 빛에 노출되어 각성이 증가되는 것을 막을 수 있었을 것이다. 본 피험자들의 주간 수면검사 시작 전 5 시간 동안의 빛 노출량 이 두 번의 실험 조건 모두에서 야간 근무 후 집으로 귀가해 서 주간 수면을 취했던 선행연구 피험자들의 취침 전 5시간 동안의 빛 노출량(616.43 \pm 509.72 lux)보다 낮았다..$^{10}$ 또한 본 실험실의 환경은 자택에서의 실제 수면 상황과 다르다는 점 이다. 검사실은 밀폐되므로 소음이 거의 완전히 차단되며,
자택에서 발생할 수 있는 기타 수면 방해 요인(가족 소음, 인 터폰, 전화 등)이 제거된 상태이기 때문에, 아무래도 연구 동 안 수면의 질이 더 높았을 가능성이 있다.

둘째, 빛 노출이 멜라토닌 분비 억제에 미치는 영향은 수 면 시간대에 따라 다를 수 있다. 생리학적으로 멜라토닌 분 비량이 많은 야간 수면 동안에는 빛 노출시간이 길수록 멜 라토닌 억제가 심화되고, ${ }^{18}$ 대뇌피질과 시상피질의 신경 활 동 동기화를 방해하여 서파 활성과 수면방추(sleep spindle) 를 감소시켜서 수면의 질을 떨어뜨린다. ${ }^{19,20}$ 하지만 본 연구 대상 야간 근무자의 경우 멜라토닌이 야간에 분비되는 일주 기리듬이 변화하지 않아 빛 노출에 의한 멜라토닌 억제 효 과가 주간 수면 동안에는 작동하지 않았을 것으로 추정한다. ${ }^{5}$ 특히 교대근무수면장애(shift work sleep disorder)를 호소하 는 근무자들은 수면장애가 없는 교대근무자들에 비해 주간 수면 시간대에 멜라토닌 분비가 매우 낮다. ${ }^{21}$ 따라서 본 연구 대상자들은 모두 수면장애, 즉 교대근무수면장애를 갖고 있 으므로 주간 수면 동안 멜라토닌 농도는 낮게 유지되고 있 었을 것이기 때문에, 빛 노출 여부에 따른 수면지표의 변화 가 없을 것으로 추정해본다. 물론 본 연구에서 시행한 주간 빛 노출 자극이 $30 \mathrm{lux}$ 로 비교적 낮아서, 멜라토닌 분비에 영향을 미치지 못할 수준이었을 가능성도 높다. 본 연구에서 30 lux의 비교적 dim light 범주에 들어갈 수 있는 낮은 조도 를 선택한 이유는, 이전 교대근무 간호사 연구에서 실제 액 티와치로 측정한 주간 수면 동안의 조도였기 때문이다..$^{10}$ 교 대근무자들은 주간 수면 동안 커튼을 치는 등의 암실 조건 에서 수면을 취해야 한다는 수면위생을 이미 잘 숙지하고 있으며, 실제 실천하고 있다. 그럼에도 불구하고 수면장애를 호소하였기에 $30 \mathrm{lux}$ 정도의 빛도 수면을 방해할 것으로 추 정을 했지만, 실제 수면지표 자체는 차이가 없게 나왔다. 그 러나 선행연구에서도 주간 수면 중 조도량을 액티와치로 측 정하였기 때문에 이불을 덮거나 해서 액티와치가 가려지는 경우 빛 노출량이 적게 평가되었을 가능성도 있다. ${ }^{10}$ 한편 모 의 야간 근무(simulated night work)를 마친 후 시행된 주간 수면 동안 3,000 lux 이상, 그리고 $\operatorname{dim} \operatorname{light}(<50 \mathrm{lux}$ )로 나누 어 수면지표와 멜라토닌 분비량을 조사한 최근 연구에서도 빛 노출군에서 멜라토닌 분비량은 차이가 없고 dim light of melatonin onset(DLMO)만 약간 진전되는 것 외에 주간 수 면의 수면지표나 일주기리듬 변화에는 큰 영향을 주지는 못 한 것으로 나타나,22 교대근무수면장애는 빛 외의 다른 요인 도 관여함을 시사한다.

셋째, 빠른 주기로 변경되는 교대근무로 인해 나타난 결과 이다. 본 연구에 참여한 대상자의 근무 일정은 이틀 연속 주 간 근무와 연이은 이틀 연속 야간 근무로, 그중 첫 번째 야간 
근무 후 주간 수면을 측정한 것이다. 일주기리듬이 2일 간격 의 주야 교대에 신속하게 맞춰졌을 것으로 생각되지 않는다. 실제 이들의 일주기리듬을 평가하지는 않았지만, 주야 어느 상황에도 제대로 적응하지 못하는 일주기리듬을 갖고 있을 가능성이 높다. 이 경우 교대근무자들의 수면을 주관하는 것 을 일주기리듬에 의한 기전(process $\mathrm{C}$ )보다는 수면박탈에 의한 homeostatic pressure(process $\mathrm{S}$ )일 것으로 추정한다. 본 연구 교대근무자들이 자가 보고한 수면시간에 따르면 야 간 근무를 시작하기 전 이틀 연속 주간 근무를 마친 후 수면 을 취하고 일어난 시간은 대략 오전 10시(7:00 14:30 clock time)로 다음 날 야간 근무 후 다시 주간 수면을 취할 때까지 거의 23 시간을 깨어 있게 된다. 이는 급성 수면박탈 상태로 간주할 수 있다. 이와 같은 강력한 homeostatic sleep pressure drive에 의해 수면지표가 비교적 정상수준으로 나타났 을 것으로 추정한다.

연구 조건 1(30 lux)과 2(<5 lux) 각각 실험 동안, 주간 수 면 전후 약 36 시간 동안 측정된 액티와치 결과를 분석해보 면, 주간 수면 동안에는 양 조건 모두에서 낮 11시에 rest period가 가장 많고, 낮 12시부터 점차 줄어드는 양상을 보 였다. 피험자들의 평소 취침시간이 09:00 10:00임을 감안하 면, 첫 수면주기를 지나면서 점차 각성빈도가 증가한다고 볼 수 있다. 반면 야간시간 동안의 활동량을 분석하면, 근무시 간 동안 rest period가 상당 수 관찰되었으며, 특히 새벽 2 3 시에 가장 높았다. 근무자들이 그 시간에 실제 잤을지는 확 인할 수 없으나, 졸았을 가능성은 있다. 첫 야간 근무보다 연 속 두 번째 야간 근무 동안, 특히 새벽 2 5시 사이에 rest pe$\operatorname{riod}$ 가 증가한 것은 야간 근무 후 정상 수면의 질로 5 시간의 수면을 취했더라도 여전히 야간 근무 동안의 각성도를 유지 하기 어렵다는 뜻이며, 야간 근무의 어려움을 보여준다고 할 수 있겠다.

그 외 흥미로운 결과는 주간 수면 동안의 렘수면 분포의 변화이다. 렘수면 총량은 상근자의 야간 수면과 차이가 없으 나, 수면의 후반부가 아닌 초반부(주로 첫 번째 사이클)에 렘 수면이 가장 길게 발현되었으며, 10 명 중 3명에서 입면 시 렘 수면(sleep onset REM sleep)이 관찰되었다. 야간 교대근무 자의 수면 동안 렘수면은 대개 첫 두 번의 수면주기에서만 나타났다는 다른 연구결과와 유사하다. ${ }^{23}$ 20대 성인에서 40 시간 수면박탈 후 시행한 회복 수면에서 수면주기(sleep cycle)가 경과하면서 REM density 증가가 억제되었다고 한 다. ${ }^{24}$ 결국 렘수면의 전진 배치는 본 대상자들의 일주기리듬 이 야간 근무에 제대로 맞춰지지 못했고, 더불어 수면박탈도 심함을 시사한다.

결론적으로, 2 교대 근무자들에서 주간 수면 중 빛 노출(30 lux)은 수면의 질이나 기상 후 집중도에 큰 영향을 주지 않았 다. 이는 연속 2 일씩 돌아가는 빠른 교대근무는 일주기리듬 을 제대로 이동시키지 못하기 때문에 근무 중 각성장애, 주 간 수면 중 수면 유지의 어려움을 초래하는 것을 알 수 있 다. ${ }^{22}$ 부적절한 수면은 졸음을 초래해서 근무 중 사고나 운전 중 교통사고 위험을 증가시킴을 고려할 때, 8,25 교대근무를 잘 적응할 수 있는 적절한 근무양식의 개발과 가장 졸리는 야간 근무 시간대에 교대로 짧은 잠을 자게 하는 중재가 필 요할 것으로 생각된다.

본 연구의 제한점으로는 예비연구로 표본 수가 적고, 2 일 연속 주간 근무 후 이어지는 1 일 야간 근무 후 시행한 하루 동안의 주간 수면만 측정했다는 점, 야간 근무 후 주간 수면 에 영향을 줄 수 있는 주간 근무 시 수면을 보다 객관적으로 조사하지 못한 점, 주간 수면 시간의 빛 자극 조절 외에는 기 타 수면에 영향을 줄 수 있는 자극을 조절하지 않아 연구결 과를 해석하는 데 제한점이 있다. 또한 주간 수면 중 빛 노출 조건에서 빛의 강도가 낮아서 암실수면과 비교해서 수면지 표에 차이가 없었을 가능성이 있고, 주간 수면이 끝나자마자 5 분 이내에 PVT를 시행하여 각성도나 집중도가 좋지 않게 평가되었을 가능성이 있다. 그러나 실제 근무를 하는 간호사 를 대상으로 하였고 주간 수면을 보다 객관적인 수면다원검 사로 평가했다는 데 의의가 있다. 향후 충분한 피험자에서 예비연구와 같은 결과를 보이는지, 노출 빛 강도를 높였을 경우 수면지표가 차이가 있는지, 동시에 일주기리듬을 평가 하는 바이오마커가 추가된 연구가 필요하다.

\section{Conflicts of Interest}

The authors have no potential conflicts of interest to disclose.

\section{Acknowledgments}

This study was supported by the Research Grant of Korean Sleep Research Society in 2018.

\section{ORCID iDs}

$\begin{array}{ll}\text { Su Jung Choi } & \text { https://orcid.org/0000-0003-2171-7441 } \\ \text { Hea Ree Park } & \text { https://orcid.org/0000-0002-7152-0754 } \\ \text { Eun Yeon Joo } & \text { https://orcid.org/0000-0003-1233-959X }\end{array}$

\section{Author Contributions}

Conceptualization: Su Jung Choi, Hea Ree Park, Eun Yeon Joo. Data curation: Su Jung Choi, Eun Yeon Joo. Formal analysis: Su Jung Choi. Funding acquisition: Eun Yeon Joo. Investigation: Su Jung Choi, Hea Ree Park. Methodology: Su Jung Choi, Hea Ree Park, Eun Yeon Joo. Project administration: Su Jung Choi, Hea Ree Park. Resources: Su Jung Choi, Hea Ree Park, Eun Yeon Joo. Software: Su Jung Choi. Supervision: Eun Yeon Joo. Validation: Su Jung Choi, Hea Ree Park, Eun Yeon Joo. Visualization: Su Jung Choi, Eun Yeon Joo. Writing-original draft: Su Jung Choi, Eun Yeon Joo. Writing—review \& editing: Su Jung Choi, Hea Ree Park, Eun Yeon Joo. 


\section{REFERENCES}

1. Lee JT, Lee KJ, Park JB, Lee KW, Jang KY. The relations between shiftwork and sleep disturbance in a university hospital nurses. Ann Occup Environ Med 2007;19:223-230.

2. Scott LD, Arslanian-Engoren C, Engoren MC. Association of sleep and fatigue with decision regret among critical care nurses. Am J Crit Care 2014;23:13-23.

3. Dorrian J, Lamond N, van den Heuvel C, Pincombe J, Rogers AE, Dawson D. A pilot study of the safety implications of Australian nurses' sleep and work hours. Chronobiol Int 2006;23:1149-1163.

4. Foreman MD, Wykle M. Nursing standard-of-practice protocol: sleep disturbances in elderly patients. The NICHE Faculty. Geriatr Nurs 1995;16:238-243.

5. Grundy A, Sanchez M, Richardson H, et al. Light intensity exposure, sleep duration, physical activity, and biomarkers of melatonin among rotating shift nurses. Chronobiol Int 2009;26:1443-1461.

6. Akerstedt T, Nordin M, Alfredsson L, Westerholm P, Kecklund G. Sleep and sleepiness: impact of entering or leaving shiftwork--a prospective study. Chronobiol Int 2010;27:987-996.

7. Scott LD, Rogers AE, Hwang WT, Zhang Y. Effects of critical care nurses' work hours on vigilance and patients' safety. Am J Crit Care 2006;15:30-37.

8. Yi YH, Choi SJ. Association of sleep characteristics with medication errors for shift work nurses in intensive care units. J Korean Acad Fundam Nurs 2014;21:403-412.

9. Touitou Y, Reinberg A, Touitou D. Association between light at night, melatonin secretion, sleep deprivation, and the internal clock: health impacts and mechanisms of circadian disruption. Life Sci 2017;173:94-106.

10. Choi SJ, Joo EY. Light exposure and sleep-wake pattern in rapidly rotating shift nurses. J Sleep Med 2016;13:8-14.

11. Cho JR, Joo EY, Koo DL, Hong SB. Let there be no light: the effect of bedside light on sleep quality and background electroencephalographic rhythms. Sleep Med 2013;14:1422-1425.

12. Blatter K, Graw P, Münch M, Knoblauch V, Wirz-Justice A, Cajochen C. Gender and age differences in psychomotor vigilance performance under differential sleep pressure conditions. Behav Brain Res 2006; 168:312-317.
13. Berry RB, Brooks R, Gamaldo C, et al. AASM Scoring Manual updates for 2017 (version 2.4). J Clin Sleep Med 2017;13:665-666.

14. Kim JW. Quantitative analysis of actigraphy in sleep research. Sleep Med Psychophysiol 2016;23:10-15.

15. Morin CM. Insomnia: psychological assessment and management. New York: Guilford Press, 1993.

16. Cho YW, Lee JH, Son HK, Lee SH, Shin C, Johns MW. The reliability and validity of the Korean version of the Epworth sleepiness scale. Sleep Breath 2011;15:377-384.

17. Park YM, Seo YJ, Matsumoto K. The Morningness-Eveningness Questionnaire in Korean version and its relations with sleep-wake habits. $J$ Ergon Soc Korea 1996;15:37-49.

18. Aoki H, Yamada N, Ozeki Y, Yamane H, Kato N. Minimum light intensity required to suppress nocturnal melatonin concentration in human saliva. Neurosci Lett 1998;252:91-94.

19. Cajochen C, Kräuchi K, Danilenko KV, Wirz-Justice A. Evening administration of melatonin and bright light: interactions on the EEG during sleep and wakefulness. J Sleep Res 1998;7:145-157.

20. Marshall L, Helgadóttir H, Mölle M, Born J. Boosting slow oscillations during sleep potentiates memory. Nature 2006;444:610-613.

21. Gumenyuk V, Roth T, Drake CL. Circadian phase, sleepiness, and light exposure assessment in night workers with and without shift work disorder. Chronobiol Int 2012;29:928-936.

22. Nagashima S, Osawa M, Matsuyama H, Ohoka W, Ahn A, Wakamura T. Bright-light exposure during daytime sleeping affects nocturnal melatonin secretion after simulated night work. Chronobiol Int 2018; 35:229-239.

23. Akerstedt T, Kecklund G, Knutsson A. Spectral analysis of sleep electroencephalography in rotating three-shift work. Scand J Work Environ Health 1991;17:330-336.

24. Marzano C, De Simoni E, Tempesta D, Ferrara M, De Gennaro L. Sleep deprivation suppresses the increase of rapid eye movement density across sleep cycles. J Sleep Res 2011;20:386-394.

25. Nakata A. Effects of long work hours and poor sleep characteristics on workplace injury among full-time male employees of small- and medium-scale businesses. J Sleep Res 2011;20:576-584. 